\title{
The effect of a diet supplemented with sea-buckthorn pomace on the colour and viscosity of the egg yolk
}

\author{
Petr Dvořák ${ }^{1}$, Pavel Suchý ${ }^{2}$ Eva Straková2, Jana Doležalová ${ }^{1}$
}

University of Veterinary and Pharmaceutical Sciences Brno, Faculty of Veterinary Hygiene and Ecology,

${ }^{1}$ Department of Gastronomy, ${ }^{2}$ Department of Animal Nutrition, Brno, Czech Republic

Received May 2, 2017

Accepted October 2, 2017

\begin{abstract}
Sea-buckthorn pomace is a very valuable product which contains not only important nutrients but also high-quality oils. The question addressed in the present study was to what extent the diet containing the sea-buckthorn pomace would affect the viscosity and colour of egg yolk measured in the CIELAB system. The feeding mixture for laying hens was supplemented with $20 ; 50$ and $100 \mathrm{~g} \cdot \mathrm{kg}^{-1}$ of sea-buckthorn pomace. As a result, colour indices of the egg yolk such as $\mathrm{L}^{*}, \mathrm{a}^{*}$ and $b^{*}$ changed significantly $(\alpha=0.01)$. The greatest relative enhancement was observed for indicator a* for the red colour. Visually, this corresponds to the more intense orange colour of the egg yolk. The addition of sea-buckthorn pomace to the diet for laying hens resulted in a larger increase in indicator $\Delta E^{*}$ (CIE total colour difference) compared to the control group. Colour indicator $\mathrm{h}_{\mathrm{ab}}$ is the only indicator whose value oscillated around that determined for the control group. The addition of sea-buckthorn pomace to the diet resulted in an increase in colour indices a*, b* and $\mathrm{C}^{*}{ }_{\mathrm{ab}}$. Indicator $\Delta E^{*}$ also increased significantly with an increasing amount of sea-buckthorn pomace in a diet. Egg yolks were darker, had more intense red and yellow colours, and showed lower viscosity which are all features preferred by the consumer.
\end{abstract}

CIELAB, addition feeding, food quality, biophysical indicators of food

Hippophae rhamnoides (common sea-buckthorn) is the most commonly used species to make sea-buckthorn oil. The plant is native to Finland and has 9 subspecies (Kallio et al. 2002). Sea buckthorn is valued for its antioxidant, cardioprotective, antiatherogenic, antidiabetic, hepatoprotective, anti-carcinogenic, immunomodulatory, antiviral, antibacterial, anti-inflammatory and vasorelaxant effects. Due to these and other positive effects, the plant is included in both human and animal nutrition, in the latter case to increase the biological value of animal products (Krejcarova et al. 2015). It is characterized by a high content of oil that is present in seeds and some soft parts of the plant (pulp and skin). The content of oil in seeds is usually around $100 \mathrm{~g} \cdot \mathrm{kg}^{-1}$ but can reach up to $150-160 \mathrm{~g} \cdot \mathrm{kg}^{-1}$ in some varieties. Unlike seeds, the content of oil in the plant's soft parts including whole berries varies depending on the origin and other factors. The content of oil in fresh berries may vary from $14 \mathrm{~g} \cdot \mathrm{kg}^{-1}$ (in the subspecies sinensis that occurs in China) to $137 \mathrm{~g} \cdot \mathrm{kg}^{-1}$ in the subspecies turkestanica that grows in the western Pamir Mountains. The content of oil in berries within one population correlates well with morphological characteristics such as the size and colour of berries, which can lead to a two-fold difference. The content of oil in berries depends on the period of harvesting (Yang and Kallio 2002a).

Oil made of sea-buckthorn seeds is rich in two essential fatty acids: linoleic acid $(18: 2, n-6)$ and alpha-linolenic acid (18:3, n-3) whose concentrations in oil can reach up to $300-400 \mathrm{~g} \cdot \mathrm{kg}^{-1}$ and $200-350 \mathrm{~g} \cdot \mathrm{kg}^{-1}$, respectively. Other major fatty acids contained in oil made of sea-buckthorn seeds are: oleic acid (18:1n-9) $130-300 \mathrm{~g} \cdot \mathrm{kg}^{-1}$, palmitic acid (16:0) $150-200 \mathrm{~g} \cdot \mathrm{kg}^{-1}$, stearic acid (18:2) 20-50 g. kg-1, vaccenic acid (18:1, n-7) 20-40 g. $\mathrm{kg}^{-1}$ (Yang and Kallio 2002a,b).

Address for correspondence:

Jana Doležalová

Department of Gastronomy

Faculty of Veterinary Hygiene and Ecology

University of Veterinary and Pharmaceutical Sciences Brno

Palackého tř. 1946/1, 61242 Brno, Czech Republic 
The colour and viscosity of the egg yolk are among the important sensory, physicochemical and nutritional indicators to evaluate the quality of eggs.

Unlike the subjective perception of colour, colority is determined objectively using spectrocolorimetric instruments with defined parameters (Dvořák et al. 2009; Saláková 2012). Colority is defined in the International Colorimetric System CIELAB (CIE 1986, Commission Internationale de l'Eclaraige). It is based on the differences of three elemental complementary colour pairs: red-green (indicator $\mathrm{a}^{*}$ ), yellow-blue (indicator $\mathrm{b}^{*}$ ) and black-white (indicator $\mathrm{L}^{*}$ ). Specific lightness $\mathrm{L}^{*}$ as the third characteristic is a function of reflectance, i.e. of the ratio between the intensity of reflected light and the intensity of incident light from 0 (black) to 100 (white). Calculations can be used to define further indices. The distance between two points $\Delta \mathrm{E}^{*}$ (CIE total colour difference). Chroma $\mathrm{C}^{*}$ is the value by which a particular colority differs from grey. The specific angle of hue $h_{a b}$ which is usually expressed by the name of colority in relation to the colour (red, yellow, etc.) (Dvořák et al. 2009, 2012).

Egg viscosity is also one of the important indicators. It affects a number of functional and technological properties of eggs such as the whipping and emulsifying ability (Kemps et al. 2010). Viscosity as a physical indicator depends on the age of the egg, storage temperature, the $\mathrm{pH}$ value, specific weight, the water content, and the straining of the egg. The viscosity of the egg yolk is $\times 8$ higher than that of the egg white (Simeonovova et al. 2003).

This study describes variations in the colour and viscosity of the egg yolk with the amount of sea-buckthorn pomace added to a complete feeding mixture for laying hens at 20, 50, and $100 \mathrm{~g} \cdot \mathrm{kg}^{-1}$.

\section{Materials and Methods}

A total of 4 groups, each containing 20 Isa Brown hybrid combination laying hens (55 weeks old), were examined in this experiment. Laying hens were reared in cages (area of $7.5 \mathrm{~m}$ ) in the accredited experimental enclosure of the Department of Animal Nutrition, University of Veterinary and Pharmaceutical Sciences Brno. Laying hens in the control group received a complete feeding mixture without sea-buckthorn. Experimental groups of hens were fed feeding mixtures supplemented with $20 \mathrm{~g} \cdot \mathrm{kg}^{-1}$ (marked as E2 in figures and tables), $50 \mathrm{~g} \cdot \mathrm{kg}^{-1}$ (E5), and $100 \mathrm{~g} \cdot \mathrm{kg}^{-1}$ (E10) of sea-buckthorn pomace. Sea-buckthorn pomace was obtained as a side product after pressing sea-buckthorn berries (Leicora variety) in order to obtain sea-buckthorn juice. Sea-buckthorn pomace contained $200.03 \mathrm{~g} \cdot \mathrm{kg}^{-1}$ of crude protein, $130.73 \mathrm{~g} \cdot \mathrm{kg}^{-1}$ of fat, $160.72 \mathrm{~g} \cdot \mathrm{kg}^{-1} \mathrm{of}$ fibre, and $20.05 \mathrm{~g} \cdot \mathrm{kg}^{-1}$ of ash, at the dry matter content of $940.16 \mathrm{~g} \cdot \mathrm{kg}^{-1}$.

Nitrogen content was determined by the Kjeldahl method using a Buchi analyser (by Centec Automatika, spol. s.r.o., Prague, Czech Republic) and the content of nitrogenous substances was calculated by multiplying the nitrogen concentrations by a coefficient of 6.25 . Fat content was determined by the apparatus ANKOMXT10 Fat Analyzer and the fibre content by ANKOM 220 Fiber Analyzer.

A total of 20 eggs were collected from each group after a 10-day experimental period to evaluate the properties of the egg yolk.

The viscosity of the egg yolk was determined using a Rheo-viscometer. Samples in a cuvette 100 were maintained at $20^{\circ} \mathrm{C}$. The sample was poured in a cuvette and then mixed $\times 10$ using an arm with a ball on its end. The measuring range for the determination of viscosity was $0.05-106 \mathrm{~Pa} \cdot \mathrm{s}$ (i.e. $0.5-107 \mathrm{cP}$ - centipoise). Loss of precision in determination was precluded by using suitable weights to ensure that each monitored time of the corrected path $(29.28 \mathrm{~mm})$ would exceed $10 \mathrm{~s}$. Due to the volume of the cuvette, two homogenized and tempered egg yolks had to be measured at the same time. A total of 10 samples from each group were examined. The viscosity of each sample of the egg yolk was measured three times. The arithmetic mean was calculated from the three measured values and used for further evaluation. Measurements were repeated with an interval of $40 \mathrm{~s}$. The time (s) was recalculated to viscosity $(\mathrm{Pa} \cdot \mathrm{s})$ using the formulae for the corrected path method.

The determination of egg yolk colour. The egg yolk was separated from the egg white prior to measurement, placed on a Petri dish with a diameter of $50 \mathrm{~mm}$, and then covered with a thin food foil. Colour was determined in the CIELAB system using the portable spectrophotometer Colour-guide sphere spex (BYK Gardner) with the exclusion of gloss, with a d/8 $8^{\circ}$ spherical geometry, $\mathrm{D}_{65}$ light source, $10^{\circ}$ standard observer angle, and an $8 \mathrm{~mm}$ aperture. The instrument was calibrated to the food foil used, prior to measurement. All measurements were performed three times. The mean value calculated from the three measurements was used as the resultant value (Dvořák et al. 2009).

Further indicators of the CIELAB system were calculated from mean values of $\mathrm{L}^{*}, \mathrm{a}^{*}, \mathrm{~b}^{*}$ coordinates and compared. 
The distance between two points $\Delta \mathrm{E}^{*}$ (CIE total colour difference) was calculated according to the following formula:

$\Delta E^{*}=\left[\left(\Delta L^{*}\right)^{2}+\left(\Delta a^{*}\right)^{2}+\left(\Delta b^{*}\right)^{2}\right]^{1 / 2}$

Chroma $\mathrm{C}^{*}$ is the value by which the particular colority differs from grey according to the following formula: $\mathrm{C}^{*}=\left(a^{* 2^{\mathrm{ab}}}+b^{* 2}\right)^{1 / 2}$

The specific angle of hue $h_{a b}$ is described by the name of a particular colour. Its value is calculated according to the following formula:

$\mathrm{h}_{\mathrm{ab}}=\operatorname{tg}^{-1}(\mathrm{~b} * / \mathrm{a} *)$

Data were processed statistically for each indicator $\left(\mathrm{L}^{*}, \mathrm{a}^{*}, \mathrm{~b}^{*}\right)$ and viscosity (Figs 1 and 2 ). The effect of seabuckthorn pomace added in the feeding dose on colour indicators and viscosity of the egg yolk was tested using one-factor ANOVA (MS EXCEL). Since large differences were assumed in the experiment, the null hypothesis was formed for the level of significance $\alpha=0.01$.

\section{Results}

Figure 1 shows standard colority indicators of the egg yolk. Indicators $\mathrm{a}^{*}$ and $\mathrm{b} *$ increased markedly (ANOVA) with the amount of added pomace. Indicator a* increased in groups E5 and E10 in comparison with the control group. Variability documented by the standard error of the mean (SEM) was very low in all sets. Visually, egg yolks were of more intense orange colour. Indicator b, which was more variable than indicator a, correlated well with the amount of pomace in the feed. This was manifested by the saturation of the yellow colour. In contrast, indicator L decreased (ANOVA) with the amount of sea-buckthorn pomace in the feed. Variability characterized by SEM was very low. Egg yolks generally appeared to be darker.

Fig. 1. Variation in colour indicators of the egg yolk with the amount of sea-buckthorn pomace in the feed $($ Mean \pm SEM).

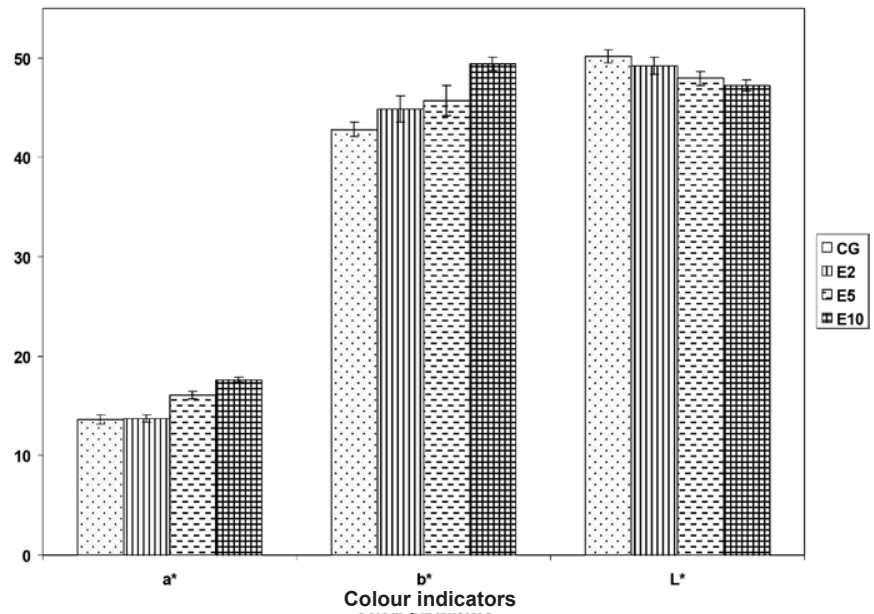

CG - Control group, E2 - the feed supplemented with $20 \mathrm{~g} \cdot \mathrm{kg}^{-1}$ of sea-buckthorn pomace, E5 - the feed supplemented with $50 \mathrm{~g} \cdot \mathrm{kg}^{-1}$ of sea-buckthorn pomace, E10 - the feed supplemented with $100 \mathrm{~g} \cdot \mathrm{kg}^{-1} \mathrm{of} \mathrm{sea}-$ buckthorn pomace

It follows from the comparison with the control group that the addition of sea-buckthorn pomace in the feed resulted in a significant increase in indicators $\mathrm{C}^{*}$ (chroma) and $\Delta E^{*}$ (CIE total colour difference) (Table 1). Both indicators increased with the amount of seabuckthorn pomace in the feed. Hue $h_{a b}$ was the only indicator whose value oscillated around that found in the control group (Table 1). 
Table 1. Variations in calculated colour indicators of the egg yolk with the amount of sea-buckthorn pomace in the feed.

\begin{tabular}{lccc}
\hline Group & $\mathrm{C}^{*}{ }_{\mathrm{ab}}$ & $\mathrm{h}_{\mathrm{ab}}$ & $\Delta \mathrm{E}^{*}$ compared to control \\
\hline CG & 44.943 & 80.420 & 0.000 \\
E2 & 46.925 & 81.134 & 2.262 \\
E5 & 48.445 & 78.449 & 4.392 \\
E10 & 52.463 & 78.158 & 8.262 \\
\hline
\end{tabular}

CG - Control group, E2 - the feed supplemented with $20 \mathrm{~g} \cdot \mathrm{kg}^{-1}$ of sea-buckthorn pomace, E5 - the feed supplemented with $50 \mathrm{~g} \cdot \mathrm{kg}^{-1}$ of sea-buckthorn pomace, E10 - the feed supplemented with $100 \mathrm{~g} \cdot \mathrm{kg}^{-1}$ of sea-buckthorn pomace

Figure 2 provides an overview of the viscosity values for the egg yolk. It shows that viscosity decreased at the lowest amount of pomace added to the feed $\left(20 \mathrm{~g} \cdot \mathrm{kg}^{-1}\right)$ but did not continue to change significantly (ANOVA) with the increasing amount of sea-buckthorn pomace in the feeding dose.

Fig. 2. Variation in the viscosity of the egg yolk with the amount of sea-buckthorn pomace in the feed $($ Mean \pm SEM).

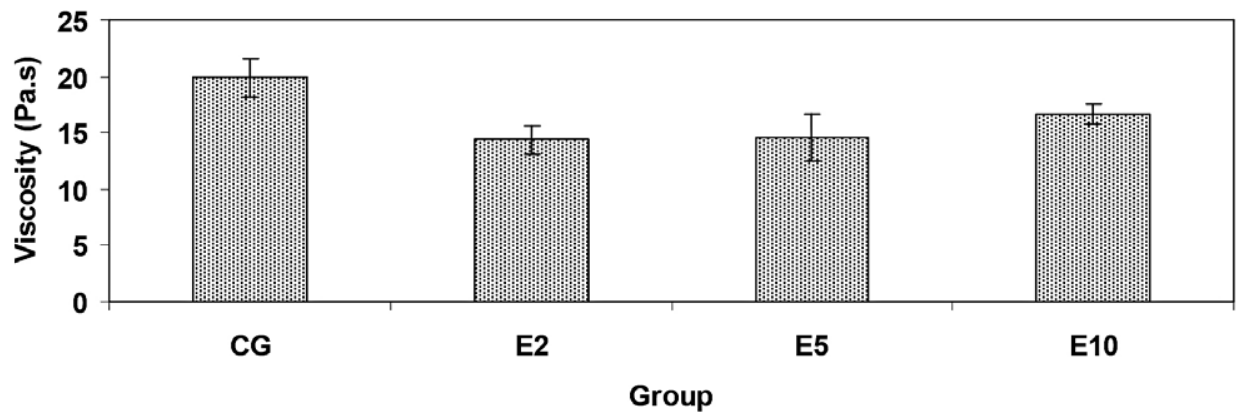

CG - Control group, E2 - the feed supplemented with $20 \mathrm{~g} \cdot \mathrm{kg}^{-1}$ of sea-buckthorn pomace, E5 - the feed supplemented with $50 \mathrm{~g} \cdot \mathrm{kg}^{-1}$ of sea-buckthorn pomace, E10 - the feed supplemented with $100 \mathrm{~g} \cdot \mathrm{kg}^{-1}$ of sea-buckthorn pomace

\section{Discussion}

Although the colour of the egg yolk improved with the amount of pomace, the differences were not as significant as when natural pigments were added into the feed (Dvořák et al. 2012). This particularly applies to indicator $\Delta E^{*}$ (Table 1) whose maximum value in our study was 8.262 whereas in the above-mentioned study it varied within the range of 17.917-24.265. Values reported in this paper are very similar to those determined for pastured laying hens as the calculated indicator $\Delta \mathrm{E}^{*}$ (total colour difference) is 13.257 (Dvořák et al. 2012), in comparison with the control group.

Dried tomato pulp can also be used in laying hens as an alternative feed. The supplementation of a diet with up to $100 \mathrm{~g} \cdot \mathrm{kg}^{-1}$ of the pulp has no negative effect on the quality of eggs (Nobakht and Safamehr 2007). Other authors reported a more intense egg yolk colour when the feeding dose for laying hens contained $100 \mathrm{~g} \cdot \mathrm{kg}^{-1}$ of dried tomato pulp to substitute wheat and maize (Mansoori et al. 2008). 
Supplementation of the feed with $50 \%$ palm kernel pomace enriched with palm oil had no negative effect on the performance of local Nigerian hens and on the quality of their eggs. The colour of the egg yolk increased significantly $(P<0.05)$ (A folabi et al. 2012). Chong et al. (2008) described the significantly lighter colour of the yolk when extracted palm kernel pomace was added in the feed for laying hens at an amount of $250 \mathrm{~g} \cdot \mathrm{kg}^{-1}$.

Supplementation of the feeding dose with $10-100 \mathrm{~g} \cdot \mathrm{kg}^{-1}$ linseed cake increased the level of thiocyanate in blood serum. However, no significant differences in indicators of egg quality between experimental and control groups were found. The composition of particular acids in lipids in the egg yolk changed. For example, the level of linolenic acid in the egg yolk increased (Richter et al. 1998). The feeding paste containing 30, 60 or $90 \mathrm{~g} \cdot \mathrm{kg}^{-1}$ of rape pomace had no significant effect on the weight and quality of eggs, except for a slight discoloration of the egg yolk (Obadalek et al. 1997).

The egg yolk viscosity decreases with the storage duration and due to thermal effects (Lucisano et al. 1996; Adamiec et al. 2002). The ovomucin-lysozyme complex plays a major role, contributing to changes in the viscosity of both the egg yolk and the egg white (Chang and Chen 2000). No correlation was shown between the viscosity and emulsifying ability of the egg yolk (Waimaleongora et al. 2009).

Variation in the egg yolk viscosity with the storage duration and temperature was studied by Severa et al. (2010). Yolks were stored for a period of 8 weeks at temperatures varying at the range of $4-16^{\circ} \mathrm{C}$. The analysis of yolks revealed the signs of shear thinning behaviour and the existence of yield stress (Ma et al. 1990). These effects were prevented by storing the yolks only for 3 days. However, viscosity decreased upon the addition of sea-buckthorn pomace to the feed. This is probably associated with a small portion of sea-buckthorn oil contained in the pomace. The addition of a small amount of sea-buckthorn pomace to the feed led to a $25 \%$ decrease in viscosity. Increasing the portion of sea-buckthorn pomace in the feed did not result in a further decrease in viscosity (Fig. 2).

When eggs were irradiated with gamma-radiation at a dose up to $3 \mathrm{kGy}$, the viscosity of the fluid egg white decreased. This led to increased emulsifying ability, whipping performance and greater stability of foam made of the egg white. In contrast, the viscosity of the egg yolk increased upon irradiation (Ma et al. 1990).

The addition of sea-buckthorn pomace in the feed increases the values of colour indicators $\mathrm{a}^{*}, \mathrm{~b}^{*}$ and $\mathrm{C}_{\mathrm{ab}}^{*}$. Indicator $\Delta E^{*}$ significantly increases, depending on the amount of pomace added to the feed. Yolks are darker and of a more intense red and yellow colour. A significant $25 \%$ decrease in viscosity was detected for the lowest amount of sea-buckthorn pomace added to the feed.

\section{References}

Adamiec J, Doležal J, Míková K, Davídek J 2002: Changes in egg volatiles during storage. Czech J Food Sci 20: $79-82$

Afolabi KD, Akinsoyinu AO, Omojola AB, Abu OA 2012: The performance and egg quality traits of Nigerian local hens fed varying dietary levels of palm kernel cake with added palm oil. J Appl Poult Res 21: 588-594

Chang YI, Chen TC 2000: Functional and gel characteristics of liquid whole egg as affected by $\mathrm{pH}$ alteration. J Food Eng 45: 237-241

CIE 1986: Colorimetry, $2^{\text {nd }}$ edn, CIE Publications No. 15.2. Commission Internationale de 1'Eclaraige, Vienna

Chong CH, Zulkifli I, Blair R 2008: Effects of dietary inclusion of palm kernel cake and palm oil, and enzyme supplementation on performance of laying hens. Asian Australas J Anim Sci 21: 1053-1058

Dvořák P, Doležalová J, Suchý P 2009: Photocolorimetric determination of yolk colour in relation to selected quality parameters of eggs. J Sci Food Agric 89: 1886-1889

Dvoŕák P, Suchý P, Straková E, Kopřiva V 2012: Possibilities of enhancing the colour of egg yolk. J Sci Food Agric 92: 853-856

Kallio H, Yang B, Peippo P, Tahvonen R, Pan R 2002: Triacylglycerols, glycerophospholipids, tocopherols and tocotrienols in sea buckthorn Hippophae rhamnoides L. ssp. sinensis and ssp. mongolica berries and seeds. J Agric Food Chem 50: 3004-3009 
Kemps BJ, Bamelis FR, Mertens K, Decuypere EM, De Baerdemaeker JG, De Ketelaere B 2010: The assessment of viscosity measurements on the albumen of consumption eggs as an indicator for freshness. Poult Sci 89: 2699-2703

Krejcarova J, Strakova E, Suchy P, Herzig I, Karaskova K 2015: Sea buckthorn (Hippophae rhamnoides L.) as a potencial source of nutraceutics and its therapeutic possibilities a review. Acta Vet Brno 84: 257-268

Lucisano M, Hidalgo A, Comelli EM, Rossi M 1996: Evolution of chemical and physical albumen characteristics during the storage of shell eggs. J Agric Food Chem 44: 1235-1240

Ma CY, Sahasrabudhe MR, Poste LM, Harwalkar VR, Chambers JR, Ohara KPJ 1990: Gamma-irradiation of shell eggs - internal and sensory quality, physicochemical characteristic, and functional properties. Canadian Institute of Food Science and Technology Journal: Journal de 1'Institut canadien de science et technologie alimentaire 23: 226-232

Mansoori B, Modirsanei M, Kiaei MM 2008: Influence of dried tomato pomace as an alternative to wheat bran in maize or wheat based diets, on the performance of laying hens and traits of produced eggs. Iran J Veterinary Res 9: 341-346

Nobakht A, Safamehr AR 2007: The effects of inclusion different levels of dried tomato pomace in laying hens diets on performance and plasma and egg yolk cholesterol contents. J Anim Vet Adv 6: 1101-1106

Obadalek J, Vymola J, Kosar K 1997: Rapeseed cake in laying hen diets. Zivocisna vyroba 42: 23-26

Richter G, Ludke H, Ochrimenko WI, Leiterer M, Huller M, Schenkel H 1998: Investigations about the use of linseed cake in laying hens. Arch Geflugelkd 62: 264-272

Saláková A 2012: Instrumental measurement of texture and color of meat products. Maso International 2: 107-114

Severa L, Nedomová Š, Buchar J 2010: Influence of storing time and temperature on the viscosity of an egg yolk. J Food Eng 96: 266-269

Simeonovova J, Mikova K, Ingr I, Kubisova S 2003: Technology of poultry, eggs, and minor animal products. Ed. by MZLU Brno, Brno, 247 p.

Waimaleongora-Ek P, Garcia KM, No HK, Prinyawiwatkul W, Ingram DR 2009: Selected quality and shelf life of eggs coated with mineral oil with different viscosities. J Food Sci 74: 423-429

Yang B, Kallio H 2002a: Composition and physiological effects of sea buckthorn (Hippophae) lipids. Trends Food Sci Technol 13: 160-167

Yang B, Kallio H 2002b: Effects of harvesting time on triacylglycerols and glycerophospholipids of sea buckthorn (Hippophae rhamnoides L.) berries of different origins. J Food Compos Anal 15: 143-157 